\title{
Synthesis of Ricinoleic Acid Estolides by the Esterification of Ricinoleic Acids Using Functional Acid Ionic Liquids as Catalysts
}

\author{
Gaoshang Wang and Shangde Sun* \\ Lipid Technology and Engineering, School of Food Science and Engineering, Henan University of Technology, Lianhua Road 100, Zhengzhou \\ 450001, Henan Province, P. R. CHINA
}

\begin{abstract}
Estolides of ricinoleic acid (RA) have been used as lubricants and pigment dispersant in many industries. In this paper, functional acid ionic liquids (ILs) were firstly used as catalysts to prepare RA estolides by the esterification of RAs in solvent-free system. Different ILs were used as catalysts for the esterification. Effect of reaction variables (IL amount, reaction temperature and reaction time) on the esterification were also investigated and optimized using response surface methodology (RSM). Among all tested ILs, $\left[\mathrm{BSO}_{3} \mathrm{HMIM}\right] \mathrm{TS}$ showed the best performance for the esterification. Arrhenius equation for the esterification was $\ln V_{0}=14.897-7558.7 / T$, and the activation energy (Ea) was $62.84 \mathrm{~kJ} / \mathrm{mol}$. A high degree of polymerization with an acid value of $48.0 \pm 2.5 \mathrm{mg} \mathrm{KOH} / \mathrm{g}$ was achieved at the optimized conditions (IL load $12 \%$, reaction temperature $140^{\circ} \mathrm{C}$, and reaction time $12 \mathrm{~h}$ ). The effect of reaction variables on the esterification decreased in the order of catalyst loading of $\mathrm{IL}>$ reaction temperature $>$ reaction time.
\end{abstract}

Key words: esterification, estolide, functional ionic liquid, ricinoleic acid, response surface methodology

\section{INTRODUCTION}

Estolides are kinds of linear oligomeric polyesters, which can be prepared by the esterification between carboxyl group and hydroxyl group of hydroxyl fatty acids ${ }^{1-3)}$. Ricinoleic acid (RA, 18:1 $\left.1^{9}-\mathrm{OH}^{12}\right)$ is an unsaturated hydroxyl fatty acid that naturally occurs in castor oil. The estolides formed by the esterification of ricinoleic acids (RA) and their derivatives, owning to their excellent lubricities and biodegradability properties, have been used in many industries ${ }^{4-6)}$, for example, as base stocks for lubricants and functional fluids, cutting oil base in metal processing, a viscosity controller for chocolate, an emulsifier for margarine, and pigment dispersant in paint, ink, cosmetics, etc..

According to those previous reports ${ }^{1,7,8)}$, ricinoleic acid estolides can be prepared by enzymatic esterification of RA. For example, free Candida rugosa lipase was used as catalyst for ricinoleic acid estolides preparation in a batch reactor $^{1)}$. The estolide with an acid value $(\mathrm{AV})$ of $65 \mathrm{mg}$ $\mathrm{KOH} / \mathrm{g}$ can be obtained at $48 \mathrm{~h}$ after the removal of water formed in the reaction. In order to further improve the operational stability of reaction system, immobilized Candida rugosa lipase was used to catalyze the esterification of RA, and an estolide with high degree of polymerization (AV,
$57.5 \mathrm{mg} \mathrm{KOH} / \mathrm{g}$ ) can be obtained at $48 \mathrm{~h}$ in a vacuum reactor $^{7,9)}$.

A noncommercial immobilized Staphylococcus xylosus lipase 2 was also used to prepare ricinoleic acid estolide in presence or absence of organic solvent ${ }^{8)}$. High yield of ricinoleic acid estolide $(65 \pm 4 \%)$ was achieved at $48 \mathrm{~h}$ in a solvent-free system and the presence of molecular sieves ${ }^{8)}$. In order to effectively synthesize ricinoleic acid estolide, a bioreactor system containing immobilized lipase was used to rapidly prepare ricinoleic acid estolide with high degree of condensation ${ }^{6}$. However, due to the high cost of enzyme and low reaction efficiency of enzymatic reaction, more efficient methods and green catalysts for ricinoleic acid estolide preparation have attracted much attention.

Ionic liquids (ILs) are salts consisting of organic cations and inorganic or organic anions. ILs, as the novel environmental friendly catalysts, due to non-volatile, thermal stability, and easy separation, have been used as green solvents and catalysts for many reactions ${ }^{10-18)}$. However, the information of IL as catalyst for the synthesis of ricinoleic acid estolides was not available.

In this work, various functional ILs were used as catalysts to prepare ricinoleic acid estolides in solvent-free

\footnotetext{
*Correspondence to: Shangde Sun, Lipid Technology and Engineering, School of Food Science and Engineering, Henan University of Technology, Lianhua Road 100, Zhengzhou 450001, Henan Province, P. R. CHINA

E-mail: sunshangde@ hotmail.com

Accepted March 7, 2017 (received for review February 6, 2017)

Journal of Oleo Science ISSN 1345-8957 print / ISSN 1347-3352 online

http://www.jstage.jst.go.jp/browse/jos/ http://mc.manusriptcentral.com/jjocs
} 


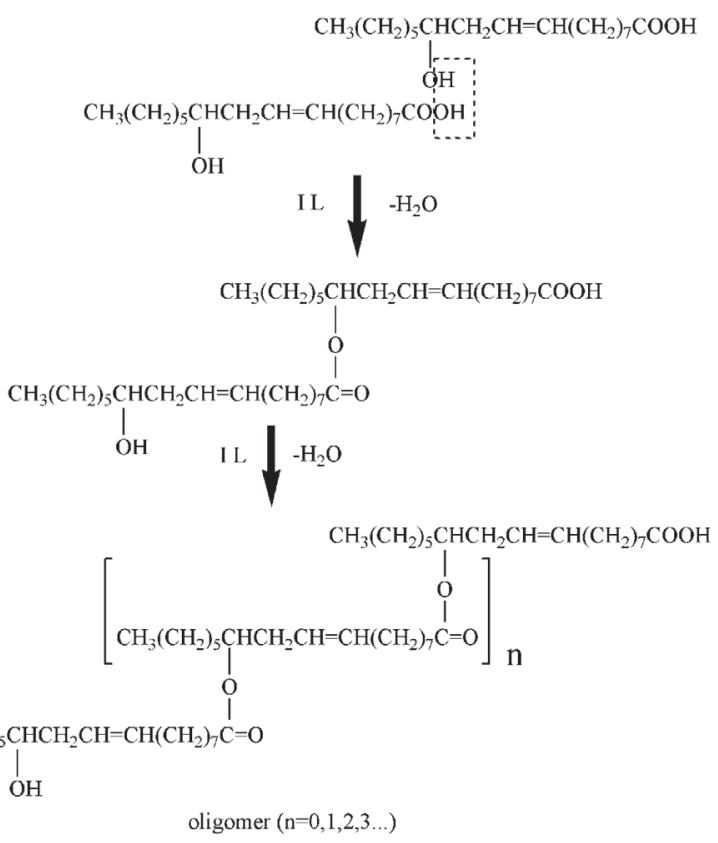

Fig. 1 Synthesis of estolides by the esterification of ricinoleic acids catalyzed using ionic liquids (ILs).

system(Fig. 1). Compared with those previous reports using lipases as catalysts, ricinoleic acid estolides can be efficiently prepared using functional ILs as catalysts. And the effect of reaction variables (ILs amount, reaction temperature, and reaction time) on the preparation of ricinoleic acid estolides were also investigated and optimized using response surface method (RSM). The relationship between initial reaction rate and reaction temperature was established, and the activation energy $(\mathrm{Ea})$ of the esterification was also evaluated.

\section{EXPERIMENTAL}

\subsection{Materials}

Ricinoleic acid $(>97.0 \%(\mathrm{~T}),>70 \%(\mathrm{GC}))$ was purchased from Aladdin (Shanghai, China). Ionic liquids (ILs): 1-butylsulfonic-3-methylimidazolium tosylate ( $\mathrm{BSSO}_{3} \mathrm{HM}$ IM]TS) , 1-butylsulfonic-3-methylimidazolium hydrogensulfate ( $\left[\mathrm{BSO}_{3} \mathrm{HMIM}\right] \mathrm{HSO}_{4}$ ), 1-butylsulfonic-3-methylimidazolium trifluoromethanesulfonate $\left(\left[\mathrm{BSO}_{3} \mathrm{HMIM}\right] \mathrm{OTF}\right)$ and 1-butylsulfonic-3-methylimidazolium hydrophosphate $\left(\left[\mathrm{BSO}_{3} \mathrm{HMIM}\right] \mathrm{HPO}_{4}\right)$ were purchased from Shanghai Cheng Jie Chemical Co. Ltd (Shanghai, China). Ethyl acetate ( $>$ 99.5\% purity) was purchased from Tianjin Kemiou Chemical Reagent Co. Ltd(Tianjin, China). All other solvents were analytical grade.

\subsection{The esterification of RAs}

The esterification of RAs were carried out in $250-\mathrm{mL}$ three-necked glass flacks, equipped with a reflux condens- er and magnetic stirrer at $500 \mathrm{r} / \mathrm{min}$, in oil bath. In a typical run, the mixture of RA $(50 \mathrm{~g})$ was catalyzed by different ILs $\left(10 \%\right.$, relative to the weight of RA) at $140^{\circ} \mathrm{C}$. Samples were withdrew, eluted and centrifuged, and the AV of the supernatant liquid was determined.

\subsection{Measurement of the reaction extension}

The degree of reaction were evaluated using acid values (AVs), which correspond to the carboxyl group concentration in the reaction mixture. In addition, the decrease in AVs can reflect the condensation of RA, which had been confirmed by HPLC ${ }^{1)}$. AVs were analyzed according to AOCS Cd 3d-63 and AOCS Ca $5 \mathrm{a}-40^{19)}$. The AVs (mg KOH/ $\mathrm{g}$ ) of ricinoleic acid estolides were determined as follows:

$$
\mathrm{AV}=56.1 \mathrm{VC} / \mathrm{W}
$$

where $\mathrm{V}$ and $\mathrm{C}$ are the consumed volume and concentration of $\mathrm{NaOH}$ solution, respectively. W is the weight of the sample.The initial $\mathrm{AV}\left(\mathrm{A}_{0}\right)$ of $\mathrm{RA}$ is $155.8 \pm 1.2 \mathrm{mg} \mathrm{KOH} / \mathrm{g}$.

\subsection{Experimental design for RSM and statistical analysis}

A Box-Behnken design for three independent parameters (ILs load, reaction temperature, and reaction time) was used to obtain the combination of values that optimizes the response (the AV of RA) within the region of the three dimensional observation space. The factors and levels selected were as follows: reaction time $(2,7,12 \mathrm{~h})$, reaction temperature $\left(90,120,150^{\circ} \mathrm{C}\right)$, and IL load $(0.1,10,19.9 \%)$.

The model evaluates the effect of each independent variable on the $\mathrm{AV}$ of RA. $3^{\mathrm{k}}$ factorial tests allow efficient estimation of a second order polynomial regression. The mathematical relationship relating the reaction variables to the AV of RA can be calculated by the following quadratic polynomial equation:

$$
Y=\beta_{o}+\sum_{i=1}^{3} \beta_{i} X_{i}+\sum_{i=1}^{3} \beta_{i i} X_{i}^{2}+\sum_{i=1}^{2} \sum_{j=i+1}^{3} \beta_{i j} X_{i} X_{j}
$$

where $\mathrm{Y}$ is the $\mathrm{AV}$ of $\mathrm{RA} ; \mathrm{X}_{\mathrm{i}}$ and $\mathrm{X}_{\mathrm{j}}$ represent the independent variables; $\beta_{\mathrm{o}}, \beta_{\mathrm{i}}, \beta_{\mathrm{ii}}$, and $\beta_{\mathrm{ij}}$ are the constant, the linear term coefficient, the quadratic term coefficient, and the cross term coefficient, respectively. The experiments were carried out for analysis using Design Expert. For the present study, the coefficients of the model were also estimated.

All experiments were performed at least in triplicate. Results were expressed as average \pm S.E.M. A two-way analysis of variance (ANOVA) was used. Statistical significance was considered at $p<0.05$.

\section{RESULTS AND DISCUSSION}

\subsection{Effect of different functional ILs}

The acidity and solubility of ILs are relative to its anion, which depend on the activity of ILs as catalysts. Due to the 


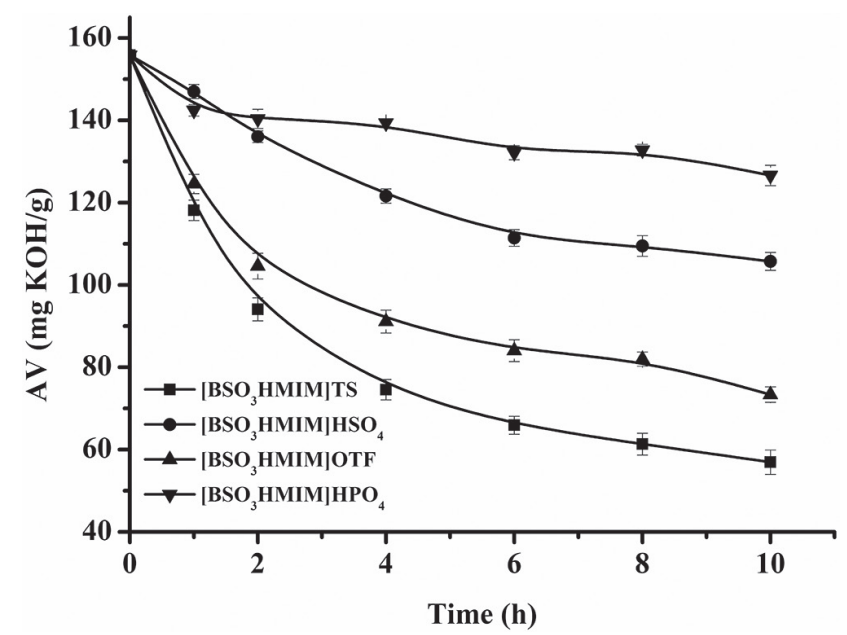

Fig. 2 Effect of various functional ILs as catalysts on the esterification of RAs. Reaction conditions: $50 \mathrm{~g}$ RAs, 5 g ILs (10\%, relative to the weight of RAs), $120^{\circ} \mathrm{C}$, and $500 \mathrm{r} / \mathrm{min}$.

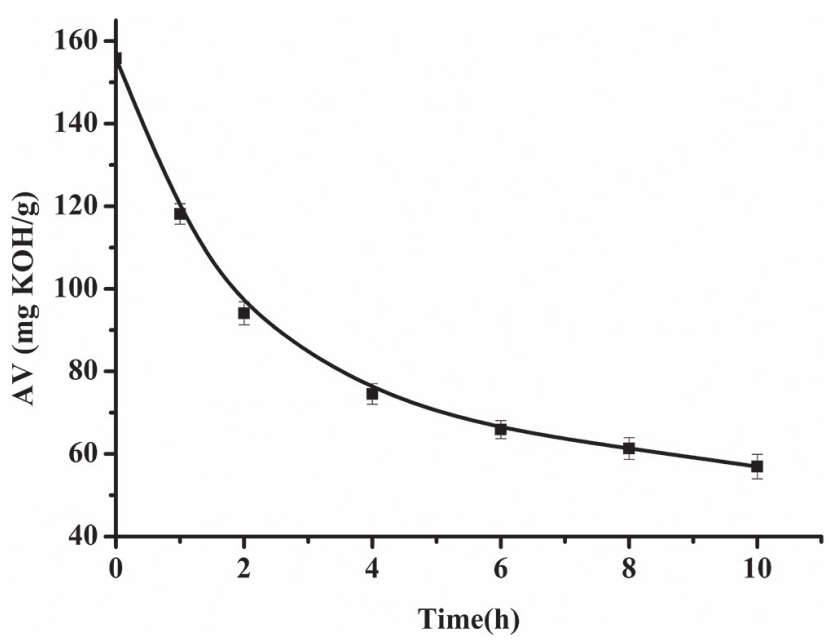

Fig. 3 Effect of reaction time on the esterification of RAs. Reaction conditions: $50 \mathrm{~g}$ RAs, $5 \mathrm{~g}\left[\mathrm{BSO}_{3} \mathrm{HMIM}\right] \mathrm{TS}$ ( $10 \%$, relative to the weight of RAs) $120^{\circ} \mathrm{C}$, and $500 \mathrm{rpm}$.

high acidities, the $\mathrm{SO}_{3} \mathrm{H}$-functioned ILs showed high activities for some esterifications ${ }^{20)}$. In the present work, the effect of different functional ILs used as catalysts for ricinoleic acid estolides preparation were compared (Fig. 2).

As shown in Fig. 2, the activities of four functional ILs as catalysts for the esterification of ricinoleic acid decreased in the order of $\left[\mathrm{BSO}_{3} \mathrm{HMIM}\right] \mathrm{TS}>\left[\mathrm{BSO}_{3} \mathrm{HMIM}\right] \mathrm{OTF}>$ $\left[\mathrm{BSO}_{3} \mathrm{HMIM}\right] \mathrm{HSO}_{4}>\left[\mathrm{BSO}_{3} \mathrm{HMIM}\right] \mathrm{HPO}_{4}$. Among the ILs tested, $\left[\mathrm{BSO}_{3} \mathrm{HMIM}\right] \mathrm{TS}$ showed the highest catalytic activity, and an estolides with a high degree of polymerization $(56.9 \pm 2.9 \mathrm{mg} \mathrm{KOH} / \mathrm{g})$ was obtained in $10 \mathrm{~h}$ (Fig. 3). The $\mathrm{AV}$ of the estolide $(56.9 \pm 2.9 \mathrm{mg} \mathrm{KOH} / \mathrm{g})$ was lower than that reported previously $(65 \mathrm{mg} \mathrm{KOH} / \mathrm{g})^{1)}$ and reaction time $(10 \mathrm{~h})$ was significant shorter than those (48 h) of lipase-
(A)

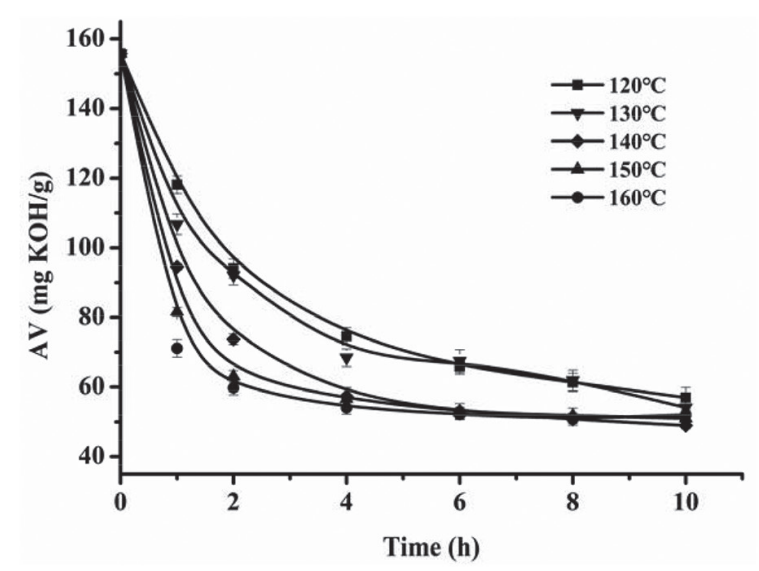

(B)

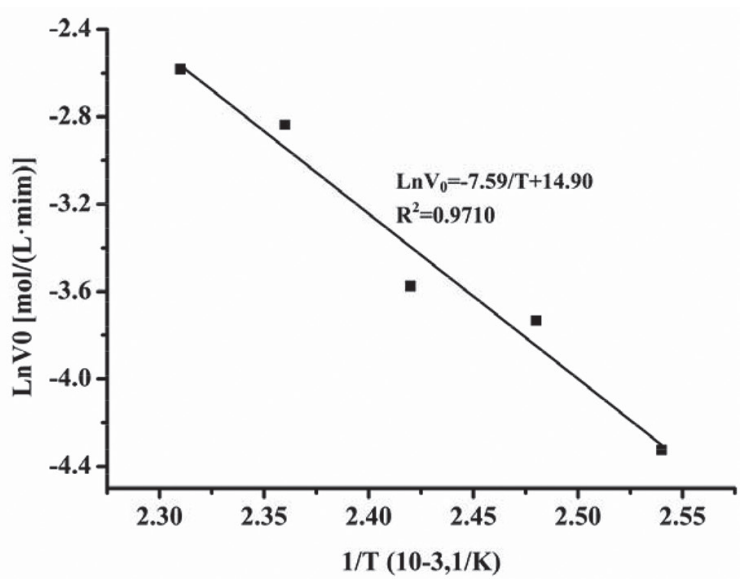

Fig. 4 (A) Effect of reaction temperature on the esterification of RAs. Reaction conditions: $50 \mathrm{~g}$ RAs, $5 \mathrm{~g}\left[\mathrm{BSO}_{3} \mathrm{HMIM}\right] \mathrm{TS}(10 \%$, relative to the weight of RAs), and $500 \mathrm{rpm}$. (B) The relationship between the initial esterification rate to form RA estolides $\left(\mathrm{V}_{0}\right)$ and reaction temperature. Reaction conditions were same as Fig. 4A.

catalyzed reactions ${ }^{1,7)}$. These results were attributed to the

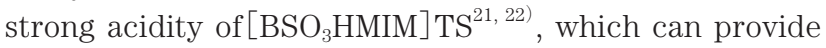
more catalytic activity sites for the esterification.

\subsection{Effect of reaction temperature on the esterification}

Reaction temperature can affect the mass transfer, catalytic activity and the miscibility of reaction system. The AV of RA significantly decreased with the increase of reaction temperature in $4 \mathrm{~h}$ (Fig. 4A). And the time that the esterification reached equilibrium shortened from $>10 \mathrm{~h}$ of $120^{\circ} \mathrm{C}$ to $6 \mathrm{~h}$ of $160^{\circ} \mathrm{C}$. When reaction temperature was $140^{\circ} \mathrm{C}$, the RA estolides with an $\mathrm{AV}$ of $48.9 \pm 0.9 \mathrm{mg} \mathrm{KOH} / \mathrm{g}$ was achieved at $10 \mathrm{~h}$, which was similar with those of $150^{\circ} \mathrm{C}(50.9 \pm 1.7 \mathrm{mg} \mathrm{KOH} / \mathrm{g})$ and $160^{\circ} \mathrm{C}(52.0 \pm 1.4 \mathrm{mg} \mathrm{KOH} /$ $\mathrm{g})$. These results showed that further increase of reaction 
temperature $\left(>140^{\circ} \mathrm{C}\right)$ did not lead to a significant increase of estolides formation.

The initial reaction rates $\left(\mathrm{V}_{0}, \mathrm{~mol} /(\mathrm{L} \cdot \mathrm{min})\right)$ of the esterification to form RA estolides, defined as the initial RA estolide yield per unit time $\left(\mathrm{V}_{0}, \mathrm{~mol} /(\mathrm{L} \cdot \mathrm{min})\right)$, were calculated from five experimental points of the yield-time profile corresponding to the first $0.5 \mathrm{~h}$ of the reaction $(15.0 \%$ or less RA estolides yield), where the profiles were found to be approximately linear. Therefore, Arrhenius law can be described as follows:

$$
\ln \mathrm{V}_{0}=\ln \mathrm{A}-\mathrm{Ea} / \mathrm{RT}
$$

where A is Arrhenius constant, Ea is the activation energy, $\mathrm{R}$ is gas constant, and $\mathrm{T}$ is absolute temperature $(\mathrm{K})$. As illustrated in Fig. 4B, a plot of $\ln \mathrm{V}_{0}$ versus $1 / \mathrm{T}$ shows a good linearity at the tested temperature. Arrhenius equation for the synthesis of RA estolides can be expressed as: $\ln \mathrm{V}_{0}=$ 14.897 - 7558.7/T, and Ea was $62.84 \mathrm{~kJ} / \mathrm{mol}$, which is higher than other Ea values $(0.97-34.5 \mathrm{~kJ} / \mathrm{mol})$ determined for the lipase-catalyzed esterifications ${ }^{23)}$.

\subsection{Effect of IL load on the esterification}

In order to investigate IL ( $\left[\mathrm{BSO}_{3} \mathrm{HMIM}\right] \mathrm{TS}$ ) load on the esterification, different IL load from $0.5 \%$ to $20 \%$ were used. As shown in Fig. 5, with the increase of $\left[\mathrm{BSO}_{3} \mathrm{HMIM}\right]$ TS load from $0.5 \%$ to $10 \%$, reaction rate increase significantly, and the minimum $\mathrm{AV}(48.9 \pm 0.9 \%)$ was achieved with $10 \%$ IL load. However, a further increase in IL load did not lead to a superior degree of polymerization (low $\mathrm{AV}$ ). In addition, an excessive IL in reaction system resulted in the increase of system viscosity, which decreased mass transfer efficiency and reaction rate. Therefore, 10\% of $\left[\mathrm{BSO}_{3} \mathrm{HMIM}\right] \mathrm{TS}$ catalyst load was used in next experiments.

\subsection{Model Fitting.}

RSM is an empirical modeling technique used to evaluate the relationship between a set of controllable experimental factors and observed results. Modeling of factors and responses was performed by RSM to predict the highest possible conversion of RA. The results obtained for the models are listed in Table 1. Duplicate experiments were carried out at all design points.

The experimental values acquired from the Box-Behnken experimental design were analyzed and regressed using a quadratic polynomial equation depicted in Eq. (4):

$$
\begin{aligned}
\mathrm{AV}(\mathrm{mg} \mathrm{KOH} / \mathrm{g})= & 56.34-25.90 \mathrm{~A}-30.25 \mathrm{~B}-12.28 \mathrm{C}+ \\
& 2.88 \mathrm{AB}+13.08 \mathrm{AC}-2.52 \mathrm{BC}+13.42 \mathrm{~A}^{2} \\
& +31.42 \mathrm{~B}^{2}+13.27 \mathrm{C}^{2}
\end{aligned}
$$

The analysis of variance (ANOVA) for this model and the significance test for each regression coefficient were shown in Table 2. The quadratic polynomial regression model was

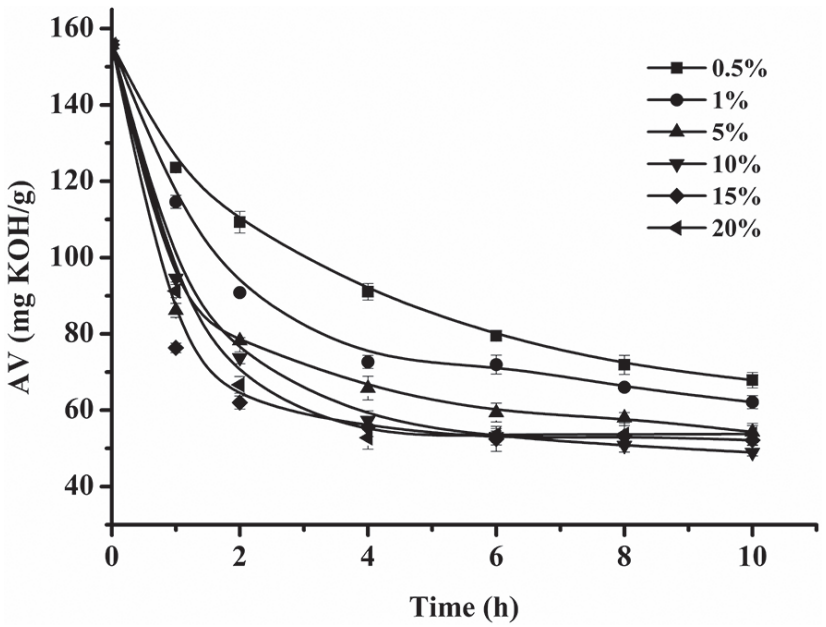

Fig. 5 Effect of $\left[\mathrm{BSO}_{3} \mathrm{HMIM}\right] \mathrm{TS}$ load on the esterification of RAs. Reaction conditions: $50 \mathrm{~g}$ RAs, $140^{\circ} \mathrm{C}$, and $500 \mathrm{rpm}$.

extremely significant $(p<0.0001)$, which indicated that the model was prominent and adequate to explain the actual relationship between the AV of RA estolides and reaction variables with a high coefficient of determination $\left(R^{2}=\right.$ $0.9823)$

The relationship between the AV of RA estolides and the interaction of reaction variables can be evaluated by $3 \mathrm{D}$ surface plots (Fig. 6). The minimum AV of the estolides obtained appeared in reaction temperature of $>130^{\circ} \mathrm{C}$, reaction time of $>6 \mathrm{~h}$, and IL load of $>10 \%$. Figure 6 also showed that the influence of the variables affecting the esterification decreased in the order of IL load $>$ reaction temperature $>$ reaction time.

Figure $6 \mathrm{~A}$ shows the mutual interaction of reaction temperature and IL load on the synthesis of ricinoleic acid estolides. The interaction of reaction temperature and IL load was the most significant. The minimum AV can be found in high temperatures $\left(>130^{\circ} \mathrm{C}\right)$ and high IL load (10 $\sim 18 \%$ ). And elliptical contours can be obtained between temperature with IL load, which indicated that the interaction of reaction temperature and IL load was very significant $^{24)}$. Figure 6B shows that, compared with reaction time, the effect of reaction temperature on the synthesis of RA estolides was more significant, which can also be found from Table 2. Figure $6 \mathrm{C}$ shows that the mutual interaction effect of IL load and reaction time in the synthesis of RA estolides at $150^{\circ} \mathrm{C}$. Low $\mathrm{AV}(<51.7 \mathrm{mg} \mathrm{KOH} / \mathrm{g})$ of RA can be obtained in high IL load $(>10 \%)$ and long reaction time $(>$ $8 \mathrm{~h}$ ). And compared reaction time, the effect of IL load was more significant, which can be also obtained from F-values (Table 2).

\subsection{Attaining optimum conditions and model verification}

Reaction conditions were optimized using RSM as follows: IL load $12 \%$, reaction temperature $140^{\circ} \mathrm{C}$, and re- 
Table 1 Response surface design and results of the preparation of RA estolides.

\begin{tabular}{ccccc}
\hline $\begin{array}{c}\text { treatment } \\
\text { No. }{ }^{a}\end{array}$ & $\begin{array}{c}\text { A, temperature } \\
\left({ }^{\circ} \mathrm{C}\right)\end{array}$ & $\begin{array}{c}\text { B, IL load } \\
(\%)\end{array}$ & $\begin{array}{c}\mathrm{C}, \text { time } \\
(\mathrm{h})\end{array}$ & $\begin{array}{c}\mathrm{AV} \\
(\mathrm{mg} \mathrm{KOH} / \mathrm{g})\end{array}$ \\
\hline 1 & 150 & 19.9 & 7 & $55.3 \pm 1.2$ \\
2 & 120 & 10.0 & 7 & $57.9 \pm 1.7$ \\
3 & 120 & 10.0 & 7 & $55.5 \pm 2.0$ \\
4 & 120 & 10.0 & 7 & $53.3 \pm 1.4$ \\
5 & 90 & 10.0 & 2 & $136.6 \pm 0.9$ \\
6 & 150 & 10.0 & 2 & $56.4 \pm 1.7$ \\
7 & 120 & 10.0 & 7 & $60.8 \pm 2.5$ \\
8 & 120 & 0.1 & 12 & $129.0 \pm 2.2$ \\
9 & 90 & 19.9 & 7 & $99.1 \pm 1.1$ \\
10 & 150 & 0.1 & 7 & $97.5 \pm 1.4$ \\
11 & 90 & 0.1 & 7 & $152.8 \pm 0.9$ \\
12 & 120 & 19.9 & 2 & $78.1 \pm 1.9$ \\
13 & 120 & 19.9 & 12 & $50.9 \pm 2.5$ \\
14 & 90 & 10.0 & 12 & $83.5 \pm 1.7$ \\
15 & 120 & 10.0 & 7 & $54.2 \pm 3.3$ \\
16 & 150 & 10.0 & 12 & $55.6 \pm 2.0$ \\
17 & 120 & 0.1 & 2 & $146.1 \pm 1.7$ \\
\hline
\end{tabular}

${ }^{a}:$ Numbers were run randomly.

Table 2 Analysis of variance(ANOVA) for quadratic model for the preparation of RA estolides.

\begin{tabular}{lccrrr}
\hline \multicolumn{1}{c}{ Source } & Sum of squares & Degrees of freedom & Mean square & F value & \multicolumn{1}{c}{ P $>$ F } \\
\hline Model & 20801.56 & 9 & 2311.28 & 43.32 & $<0.0001$ \\
A-Temperature & 5366.48 & 1 & 5366.48 & 100.58 & $<0.0001$ \\
B-ILs load & 7320.50 & 1 & 7320.50 & 137.20 & $<0.0001$ \\
C-Time & 1205.40 & 1 & 1205.40 & 22.59 & 0.0021 \\
$\mathrm{AB}$ & 33.06 & 1 & 33.06 & 0.62 & 0.4570 \\
$\mathrm{AC}$ & 683.82 & 1 & 683.82 & 12.82 & 0.0090 \\
$\mathrm{BC}$ & 25.50 & 1 & 25.50 & 0.48 & 0.5116 \\
$\mathrm{~A}^{2}$ & 758.02 & 1 & 758.02 & 14.21 & 0.0070 \\
$\mathrm{~B}^{2}$ & 4156.04 & 1 & 4156.04 & 77.89 & $<0.0001$ \\
$\mathrm{C}^{2}$ & 741.16 & 1 & 741.16 & 13.89 & 0.0074 \\
Residual & 373.50 & 7 & 53.36 & & \\
Lack of fit & 336.65 & 3 & 112.22 & 12.18 & 0.0176 \\
Pure Error & 36.85 & 4 & 9.21 & & \\
Cor Total & 21175.06 & 16 & & & \\
$\mathrm{R}^{2}=0.9824$ & & & & & \\
\hline
\end{tabular}

action time $12 \mathrm{~h}$. Under these optimal conditions, low AV $(48.0 \pm 2.5 \mathrm{mg} \mathrm{KOH} / \mathrm{g})$ of RA was achieved, which is well accorded with the predicted result ( $46.6 \mathrm{mg} \mathrm{KOH} / \mathrm{g}$ ), which indicated that the model developed was accurate and reliable. Compared with the previous report $(57.7 \mathrm{mg} \mathrm{KOH} / \mathrm{g}$ at $48 \mathrm{~h})^{7}$, lower $\mathrm{AV}(48.0 \pm 2.5 \mathrm{mg} \mathrm{KOH} / \mathrm{g})$ of $\mathrm{RA}$ can achieved in shorter time $(12 \mathrm{~h})$ in the work. 
(A)

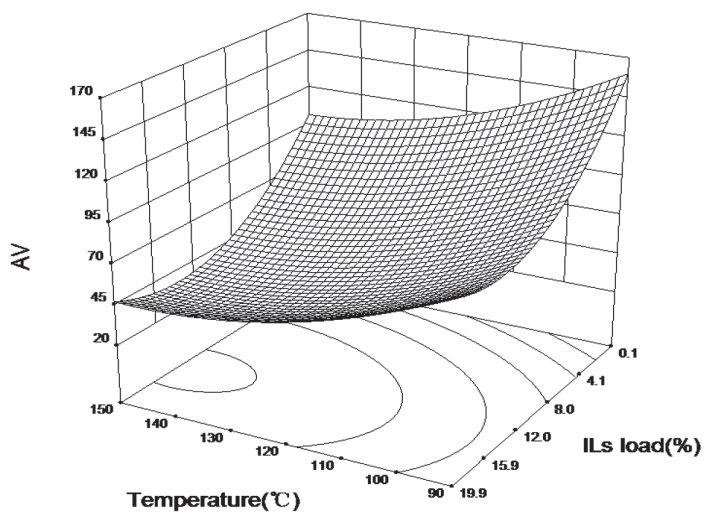

(B)

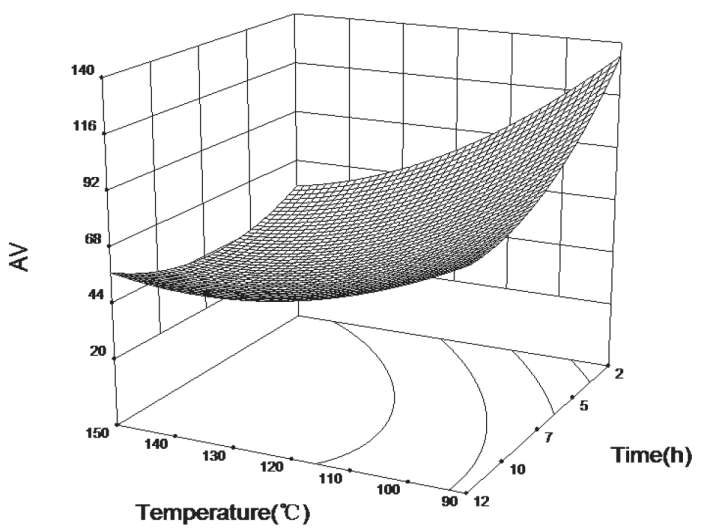

(C)

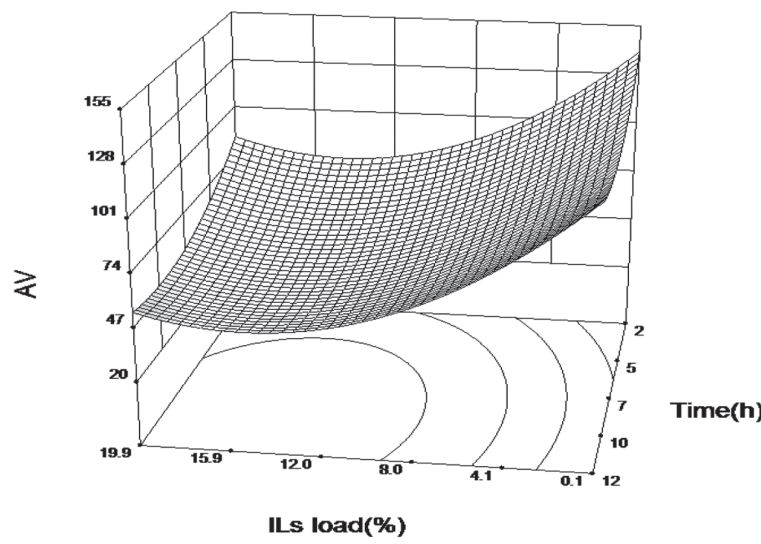

Fig. 6 (A) Response surface plot of reaction temperature and IL load with reaction time $7 \mathrm{~h}$ in the synthesis of ricinoleic acid estolides. (B) Response surface plot of reaction temperature and reaction time with $\left[\mathrm{BSO}_{3} \mathrm{HMIM}\right] \mathrm{TS}$ load $10 \%$ in the synthesis of ricinoleic acid estolides. (C) Response surface plot of IL load and reaction time with $150^{\circ} \mathrm{C}$ in the synthesis of ricinoleic acid estolides.

\section{CONCLUSION}

In the work, several functional acid ionic liquids (ILs) were used as catalysts for the esterification of RA to prepare RA estolides. Among all tested ILs, [BSO $\left.{ }_{3} \mathrm{HMIM}\right]$ TS showed the best performance for the preparation of RA estolides. The interaction effect of reaction variables were studied and optimized using RSM, and reaction conditions were optimized as follows: IL load $12 \%$, reaction temperature $140^{\circ} \mathrm{C}$, and reaction time $12 \mathrm{~h}$. The order affected the synthesis of RA estolides was IL load>reaction temperature $>$ reaction time. Under these optimal conditions, the $\mathrm{AV}$ of ricinoleic acids was $48.0 \pm 2.5 \mathrm{mg} \mathrm{KOH} / \mathrm{g}$, which is lower than those $(57.7 \mathrm{mg} \mathrm{KOH} / \mathrm{g}$ ) of previous reports using lipases as catalysts. And reaction time $(12 \mathrm{~h})$ reached equilibrium in the work is one quarter of previous report (48 h). These results showed that, compared with those previous reports using lipases as catalysts, RA estolides can be efficiently prepared using functional ILs as catalysts.

\section{Acknowledgements}

The authors gratefully acknowledge financial support from Program for Science \& Technology Innovation Talents in Universities of Henan Province (15HASTIT030), and Funding Scheme for Young Teachers Cultivating Program in Henan University of Technology.

\section{References}

1) Bódalo, A.; Bastida, J.; Máximo, M.F.; Montiel, M.C.; Murcia, M.D. Enzymatic biosynthesis of ricinoleic acid estolides. Biochem. Eng. J. 26, 155-158(2005).

2) Isbell, T.A.; Cermak, S.C. Synthesis of triglyceride estolides from lesquerella and castor oils. J. Am. Oil Chem. Soc. 79, 1227-1233(2002).

3) Isbell, T.A.; Lowery, B.A.; Dekeyser, S.S.; Winchell, M.L.; Cermak, S.C. Physical properties of triglyceride estolides from lesquerella and castor oils. Ind. Crop Prod. 23, 256-263 (2006).

4) Ebata, H.; Yasuda, M.; Toshima, K.; Matsumura, S. Poly (ricinoleic acid) based novel thermosetting elastomer. J. Oleo Sci. 57, 315-320 (2008).

5) Hayes, D.G.; Kleiman, R. Lipase-catalyzed synthesis and properties of estolides and their esters. J. Am. Oil Chem. Soc. 72, 1309-1316(1995).

6) Yoshida, Y.; Kawase, M.; Yamaguchi, C.; Yamane, T. Enzymatic synthesis of estolides by a bioreactor. J. Am. Oil Chem. Soc. 74, 261-267(1997).

7) Bódalo, A.; Bastida, J.; Máximo, M.F.; Montiel, M.C.; Murcia, M.D.; Ortega, S. Influence of the operating conditions on lipase-catalysed synthesis of ricinoleic acid estolides in solvent-free systems. Biochem. Eng. 
J. 44, 214-219(2009).

8) Horchani, H.; Bouaziz, A.; Gargouri, Y.; Sayari, A. Immobilized Staphylococcus xylosus lipase-catalysed synthesis of ricinoleic acid esters. J. Mol. Catal B: Enzym. 75, 35-42 (2012).

9) Bódalo, A.; Bastida, J.; Máximo, M.F.; Montiel, M.C. Gómez, M.; Murcia, M.D. Production of ricinoleic acid estolide with free and immobilized lipase from Candida rugosa. Biochem. Eng. J. 39, 450-456 (2008).

10) Yang, Z.; Guo, Z.; Xu, X. Ionic liquid-assisted solubilization for improved enzymatic esterification of phenolic acids. J. Am. Oil Chem. Soc. 89, 1049-1055 (2012).

11) Huang, Y.; Gao, Y.; Zhong, N. Selective production of diacylglycerols through glycerolysis by ionic liquid: 1butyl-3-methylimidazolium imidazolide as catalyst and reaction medium. J. Am. Oil Chem. Soc. 92, 927931 (2015).

12) Liao, X.; Wang, S.G.; Xiang, X.; Zhu, Y.; She, X.; Li, Y. $\mathrm{SO}_{3} \mathrm{H}$-functionalized ionic liquids as efficient catalysts for the synthesis of bioadditives. Fuel Process Technol. 96, 74-79(2012).

13) Liu, S.; Wang, A.; Liu, Z.; Li, L.; Yu, S.; Xie, C.; Liu, F. Synthesis of glycerol triacetate using a Brøsted-Lewis acidic ionic liquid as the catalyst. J. Am. Oil Chem. Soc. 92, 1253-1258(2015).

14） Moniruzzaman, M.; Nakashima, K.; Kamiya, N.; Goto, M. Recent advances of enzymatic reactions in ionic liquids. Biochem. Eng. J. 48, 295-314(2010).

15) Li, S.; Chen, X.; Chen, J.; Gong, H. Ionic liquid-promoted copper(ii)-catalyzed homocoupling of terminal alkynes in aqueous phase or under solvent-limited conditions. Bull. Chem. Soc. Jpn. 89, 794-797(2016).

16) Harada, A.; Koge, S.; Ohshita, J.; Kaneko, Y. Preparation of a thermally stable room temperature ionic liq- uid containing cage-like oligosilsesquioxane with two types of side-chain groups. Bull. Chem. Soc. Jpn. 89, 1129-1135 (2016).

17) Marr, P.C.; Marr, A.C. Ionic liquid gel materials: applications in green and sustainable chemistry. Green Chem. 18, 105-128 (2016).

18) Xia, J.; Di, J.; Li, H.; Xu, H.; Li, H.; Guo, S. Ionic liquidinduced strategy for carbon quantum $\operatorname{dots} / \mathrm{BiOX}(\mathrm{X}=$ $\mathrm{Br}, \mathrm{Cl}$ ) hybrid nanosheets with superior visible lightdriven photocatalysis. Appl. Catal. B: Environ. 181, 260-269 (2016).

19) American Oil Chemist's Society. Official Methods and Recommended Practices of the AOCS, 6th Edition, Champaign, IL (2007).

20) Li, Y.; Hu, S.; Cheng, J.; Lou, W. Acidic ionic liquid-catalyzed esterification of oleic acid for biodiesel synthesis. Chinese J. Catal. 35, 396-406 (2014).

21) Sun, S.; Chen, X.; Bi, Y.; Chen, J.; Yang, G.; Wei, L. Functionalized ionic liquid-catalyzed 1-feruloyl-snglycerol synthesis. J. Am. Oil Chem. Soc. 91, 759-765 (2014).

22) Sun, S.; Li, X. Functional ionic liquids catalyzed the esterification of ricinoleic acid with methanol to prepare biodiesel: optimization by response surface methodology. J. Am. Oil Chem. Soc. 93, 757-764(2016).

23) Balcão, V.M.; Paiva, A.L.; Malcata, F.X. Bioreactors with immobilized lipases: State of the art. Enzyme Microb. Technol. 18, 392-416(1996).

24) Marzuki, N.H.C.; Huyop, F.; Aboul-Enein, H.Y.; Mahat, N.A.; Wahab, R.A. Modelling and optimization of Candida rugosa nanobioconjugates catalysed synthesis of methyl oleate by response surface methodology. Biotechnol Biotec. Eq. 29, 1113-1127(2015). 